\title{
Dual treatment of acromegaly and hormone-receptor-positive breast cancer with tamoxifen: a case report
}

\author{
Sasan Mirfakhraee ${ }^{1,4^{*}} \mathbb{C}$, Alberto V. Cabo Chan Jr. ${ }^{2}$, Niloofar Ganji ${ }^{3}$ and Jessica Abramowitz
}

\begin{abstract}
Background: Adjuvant endocrine therapy is recommended for the treatment of hormone-receptor-positive breast cancer. Aromatase inhibitors are associated with significant musculoskeletal adverse effects, likely through growth hormone/insulin-like growth factor 1 modulation, while tamoxifen reduces insulin-like growth factor 1 production. We describe the case of a patient who was treated successfully with tamoxifen for her hormone-receptor-positive breast cancer and acromegaly.

Case presentation: A 57-year old White female with hormone-receptor-positive breast cancer was diagnosed with acromegaly. She received adjuvant endocrine therapy with anastrozole but could not tolerate this medication because of severe arthralgia, so she was switched to tamoxifen. Shortly after starting tamoxifen, the patient's musculoskeletal symptoms resolved and her insulin-like growth factor 1 levels normalized. She has remained in remission of her acromegaly and breast cancer since initiating tamoxifen.

Conclusion: This case highlights the dual benefit of tamoxifen therapy in the treatment of hormone-receptor-positive breast cancer and acromegaly. Unlike anastrozole, tamoxifen has the benefit of lowering insulin-like growth factor 1 levels, which underscores its advantage in reducing adverse musculoskeletal symptoms during the treatment of hormone-receptor-positive breast cancer. We offer the first reported use of tamoxifen monotherapy for the successful treatment of acromegaly and hormone-receptor-positive breast cancer. While tamoxifen may offer an additional, oral option for acromegaly patients who do not respond to or tolerate conventional growth-hormone-lowering therapy, additional studies are necessary.
\end{abstract}

Keywords: Acromegaly, Pituitary tumors, Growth-hormone-secreting pituitary adenoma, Case report

\section{Background}

Acromegaly is a chronic disease caused by growth hormone overproduction, most commonly by a pituitary adenoma, with characteristic bone and soft tissue changes. Individuals with acromegaly are subject to extensive comorbid illnesses and complications. An increase in neoplasia incidence with acromegaly remains

*Correspondence: Sasan.Mirfakhraee@utsouthwestern.edu

${ }^{4}$ UT Southwestern Medical Center, WCB3 8th Floor, 2001 Inwood Rd, Dallas, TX 75390, USA

Full list of author information is available at the end of the article controversial, but increased rates of breast cancer have been noted previously [1]. While on treatment with antineoplastic agents, mortality rates from cancer are higher in acromegaly patients whose growth hormone levels remain elevated, and those with reduced growth hormone levels have a mortality rate similar to the general population [2].

Hormone-receptor (that is, estrogen receptor [ER] and progesterone receptor $[\mathrm{PR}]$ ) testing is recommended for all invasive breast cancers, as this predicts which patients may benefit from adjuvant endocrine therapy. Since ERpositive breast cancers portend an increased risk of late original author(s) and the source, provide a link to the Creative Commons licence, and indicate if changes were made. The images or other third party material in this article are included in the article's Creative Commons licence, unless indicated otherwise in a credit line to the material. If material is not included in the article's Creative Commons licence and your intended use is not permitted by statutory regulation or exceeds the permitted use, you will need to obtain permission directly from the copyright holder. To view a copy of this licence, visit http://creativecommons.org/licenses/by/4.0/. The Creative Commons Public Domain Dedication waiver (http://creativeco mmons.org/publicdomain/zero/1.0/) applies to the data made available in this article, unless otherwise stated in a credit line to the data. 
recurrence, recent American Society of Clinical Oncology (ASCO) clinical practice guidelines recommend extended adjuvant endocrine therapy with aromatase inhibitors (AI) or tamoxifen for 10 years total [3]. Unfortunately, AI are associated with significant musculoskeletal adverse effects, including bone pain and arthralgia in as many as $61 \%$ of users, with up to $20 \%$ of patients discontinuing therapy because of pain [4]. While several potential etiologies have been proposed for AI-induced arthralgia [5], an intriguing possibility involves growth hormone $(\mathrm{GH}) /$ insulin-like growth factor 1 (IGF-1) modulation by AI therapy with subsequent development of adverse musculoskeletal effects. AI therapy has been shown to result in increased IGF-1 levels and an increased incidence of arthralgia in women treated for breast cancer, while tamoxifen reduced IGF-1 levels and the overall incidence of musculoskeletal side effects when used as adjuvant therapy [6].

\section{Case presentation}

A 57-year-old White female with past medical history of obstructive sleep apnea, nontoxic multinodular goiter, and hypertension underwent a routine mammogram, which revealed a focal asymmetry in the right breast; this was subsequently characterized on ultrasound as an irregular, hypoechoic solid mass with indistinct margins measuring $14 \mathrm{~mm}$. A biopsy revealed an invasive ductal carcinoma, grade 1, ER 100\%, PR 100\%, HER2/neu 1+ with a Ki-67 index of 5\%. The patient underwent partial mastectomy with sentinel node biopsy and subsequently received radiation therapy.

The patient was then referred to our endocrine clinic for treatment of her osteopenia, when it was noted that she had features consistent with growth hormone excess, including frontal bossing, jaw protrusion, wide-spaced teeth, deep voice, diaphoretic palms, and enlarged hands and feet. Symptomatically, she noted episodic headaches and diaphoresis of the hands but denied arthralgia or change in ring, shoe, or hat size. Biochemical evaluation for growth hormone excess at this time revealed an IGF-1 level of $535 \mathrm{ng} / \mathrm{mL}$ by LC/MS (reference range $50-317 \mathrm{ng} / \mathrm{mL}, Z$-score $>3$ ) and morning fasting growth hormone level of $1.57 \mathrm{ng} / \mathrm{mL}$ (reference range 0.01$3.61 \mathrm{ng} / \mathrm{mL}$ ). Two-hour oral glucose tolerance testing was performed, which showed failure of growth hormone to suppress, with a nadir level of $1.4 \mathrm{ng} / \mathrm{mL}$. Dynamic 3 Tesla magnetic resonance imaging (3T MRI) of the pituitary with gadolinium administration revealed subtle asymmetry of the right aspect of the sella without discrete lesion noted (Fig. 1).

The patient opted to address her malignancy first prior to consideration of definitive therapy of her

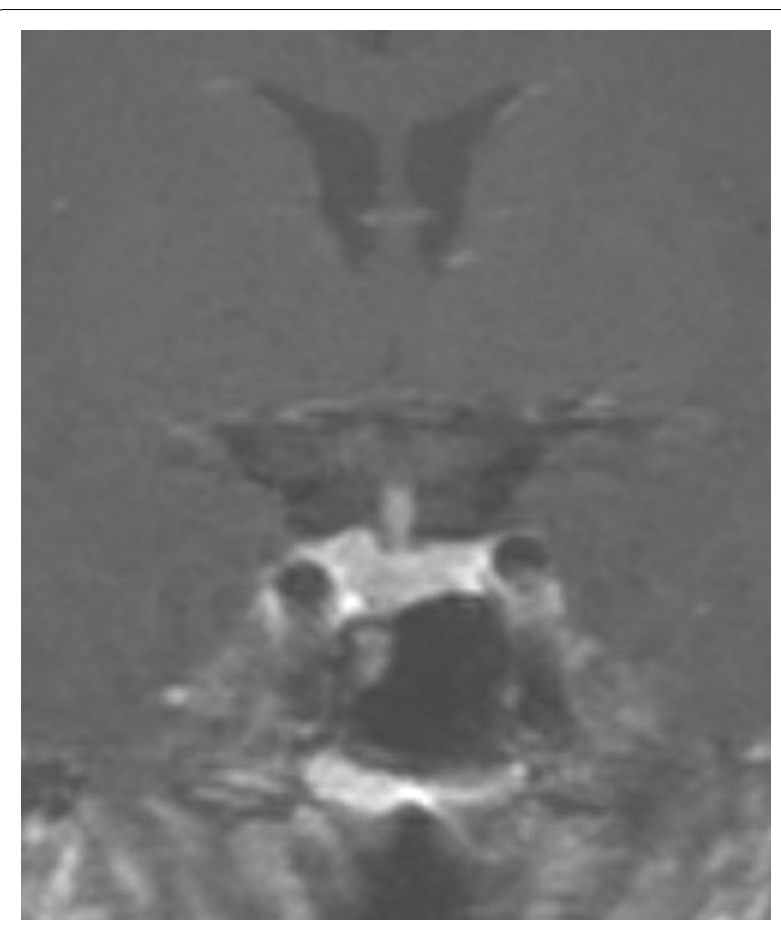

Fig. 1 T1-weighted, dynamic 3T magnetic resonance imaging of the pituitary revealing subtle asymmetry involving the right aspect of the sella without focal lesion noted

acromegaly. She was started on adjuvant endocrine therapy with anastrozole for her breast cancer but developed severe arthralgia, so was changed to tamoxifen, with prompt resolution of her headache and musculoskeletal symptoms. Two months after tamoxifen initiation, the patient's IGF-1 levels normalized and remained within the normal reference range for over 3 years while she continued tamoxifen treatment (Fig. 2). Her growth hormone levels ranged from 1.4 to $2 \mathrm{ng} /$ $\mathrm{mL}$ while on tamoxifen therapy. Recently, the patient briefly discontinued the tamoxifen for 3 months to see if this was the cause of her diminished energy levels; her IGF-1 levels increased above the normal reference range from 249 to $446 \mathrm{ng} / \mathrm{mL}$ and her acral symptoms recurred, so she restarted tamoxifen, with successive normalization of her IGF-1 level to $205 \mathrm{ng} / \mathrm{mL}$. Repeat imaging 3 months after restarting tamoxifen therapy again failed to reveal a discrete sellar lesion.

Given the patient's excellent IGF-1 response to tamoxifen, she has opted for continued medical therapy rather than surgical exploration. When she completes her course of tamoxifen next year, she prefers to transition to oral octreotide for ongoing treatment of her acromegaly. Regarding her breast cancer, she has had no evidence of recurrence 4 years since the time of diagnosis. 
IGF-1 Levels on Anastrozole and Tamoxifen Therapy

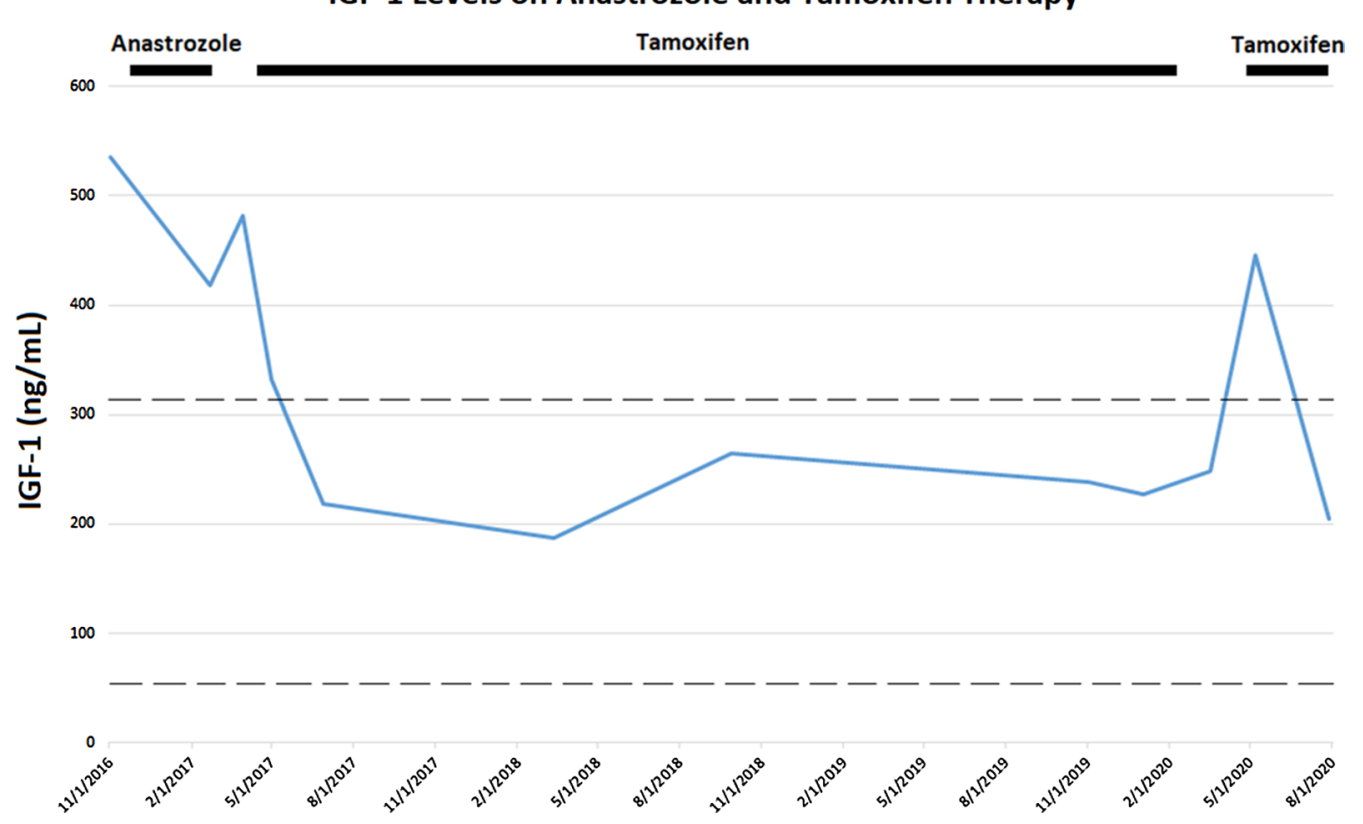

Fig. 2 IGF-1 levels (LC/MS) before and after anastrozole therapy, then while on tamoxifen therapy. Upper- and lower-normal reference ranges $(50-317 \mathrm{ng} / \mathrm{mL})$ shown as dashed lines

\section{Discussion}

Orally administered estrogen inhibits hepatic IGF-I synthesis through first-pass hepatic effect but increases GH secretion by reduced feedback inhibition [7]. This reduction in IGF-1 levels, despite an overall increase in circulating $\mathrm{GH}$, is explained by an inhibitory effect on the metabolic action of GH mediated by oral estrogen. Oral estrogen therapy attenuates $\mathrm{GH}$ signaling by inducing suppressors of cytokine signaling 2 (SOCS-2), thereby inhibiting JAK2 phosphorylation through the JAK/STAT pathway [8]. Analogous to this effect of oral estrogen, selective estrogen receptor modulators (SERMs) act as an estrogen agonist on the liver [9] and reduce IGF-1 production. This gives them a unique advantage both in the treatment of hormone-receptor positive breast cancer as well as in acromegaly. In a study of 17 subjects ( 15 men, 2 postmenopausal women) with acromegaly whose IGF-1 levels remained elevated despite conventional, GH-lowering medical therapy, the addition of tamoxifen reduced IGF-1 levels by an average of $90 \mathrm{ng} / \mathrm{mL}$ and normalized plasma IGF-1 in $47 \%$ of subjects [10]. Tamoxifen also lowered IGF-1 levels in 13 out of 19 subjects with acromegaly (6 men, 13 women), normalizing IGF-1 levels in $21 \%$ of participants [11]. Tamoxifen does not lower $\mathrm{GH}$ levels in acromegaly, however, since GH secretion remains autonomous. In a study of 16 male patients with refractory acromegaly, despite conventional therapy, the addition of clomiphene citrate, a SERM, reduced IGF-1 levels by $41 \%$ but caused a nonsignificant increase in $\mathrm{GH}$ levels [12].

The GH/IGF-1 axis plays an integral role in breast development; furthermore, when GH and IGF-1 levels are experimentally perturbed, hyperplastic lesions may develop, increasing the chances of mammary carcinoma [13]. The IGF-1 receptor is implicated in breast cancer, with up to $50 \%$ of breast tumors expressing the activated form of this receptor [14]. Circulating IGF-1 levels are also associated with breast cancer risk, with pooled data from 17 prospective studies demonstrating a positive association between IGF-1 levels and estrogen-receptorpositive cancer risk [15]. Furthermore, higher IGF-1 levels are related to reduced overall survival in breast cancer patients treated with endocrine therapy [16]. Tamoxifen lowers plasma IGF-1 levels in individuals with breast cancer [17], which may contribute to its antitumor action. While interventions aimed at inhibiting the IGF-1R have not improved outcomes in breast cancer subjects to date, various elements of study design may be contributory to this outcome [18] and further studies are ongoing.

There are two cases in the literature describing cases of acromegaly and hormone-receptor-positive breast cancer in women $[19,20]$. The first case details the response to breast cancer therapy in a woman with $\mathrm{ER}+/ \mathrm{PR}+$ metastatic disease treated concomitantly with exemestane, an AI, and octreotide for her acromegaly; the subject's breast cancer progressed when she was nonadherent with 
octreotide therapy [19]. In the second case, the IGF-1 levels of a patient with acromegaly remained elevated despite lanreotide and cabergoline therapy [20]. Shortly thereafter, the patient was diagnosed with ER+/PRbreast cancer. Tamoxifen was substituted for the patient's cabergoline, with subsequent normalization of the patient's IGF-1 levels. Our case differs from these two published cases in that our patient was not treated with conventional medical therapy for acromegaly; instead, she received initial therapy with anastrozole, which exacerbated her musculoskeletal symptoms, presumably mediated by the effect on her GH/IGF-1 axis. She was then switched to tamoxifen, which resolved her acral symptoms and normalized her IGF-1 levels. Ours is therefore the first-reported use of tamoxifen monotherapy for the successful treatment of acromegaly and hormone-receptor-positive breast cancer.

\section{Conclusion}

We report the case of a patient with hormone-receptorpositive breast cancer who was diagnosed with acromegaly prior to the initiation of adjuvant endocrine therapy. Her symptoms worsened on anastrozole but improved significantly with tamoxifen, with durable control of her acromegaly and breast cancer. This case highlights the dual benefit of tamoxifen therapy in the treatment of hormone-receptor-positive breast cancer and acromegaly. Unlike anastrozole, tamoxifen has the benefit of lowering IGF-1 levels, which underscores its advantage in reducing adverse musculoskeletal symptoms during the treatment of hormone-receptor positive breast cancer. Additionally, tamoxifen offers an additional, oral treatment option for patients with acromegaly who might not achieve biochemical targets or cannot tolerate conventional medical therapy (such as somatostatin analogs or growth hormone receptor antagonists), though additional studies are necessary.

\section{Abbreviations}

ER: Estrogen receptor; PR: Progesterone receptor; GH: Growth hormone; IGF-1: Insulin-like growth factor 1; SERMs: Selective estrogen receptor modulators.

\section{Acknowledgements}

Not applicable.

\section{Authors' contributions}

SM and JA were the main contributors in writing the manuscript. AC and NG assisted with editing and making revisions to the manuscript. All authors read and approved the final manuscript.

\section{Funding}

Not applicable.

Availability of data and materials

Not applicable.

\section{Declarations}

Ethics approval and consent to participate Not applicable.

\section{Consent for publication}

Written informed consent was obtained from the patient for publication of this case report and any accompanying images. A copy of the written consent is available for review by the Editor-in-Chief of this journal.

\section{Competing interests}

The authors have stated explicitly that there are no conflicts of interest in connection with this article.

\section{Author details \\ ${ }^{1}$ Division of Endocrinology and Metabolism, Department of Internal Medicine, University of Texas Southwestern Medical Center, Dallas, TX, USA. ${ }^{2}$ Division of Mineral Metabolism, Department of Internal Medicine, University of Texas Southwestern Medical Center, Dallas, TX, USA. ${ }^{3}$ Department of Physiology, University of Toronto, Toronto, ON, Canada. ${ }^{4}$ UT Southwestern Medical Center, WCB3 8th Floor, 2001 Inwood Rd, Dallas, TX 75390, USA.}

Received: 26 January 2021 Accepted: 16 March 2021

Published online: 29 April 2021

\section{References}

1. Nabarro JD. Acromegaly. Clin Endocrinol (Oxf). 1987;26(4):481-512.

2. Orme SM, et al. Mortality and cancer incidence in acromegaly: a retrospective cohort study. United Kingdom Acromegaly Study Group. J Clin Endocrinol Metab. 1998;83(8):2730-4.

3. Burstein $\mathrm{HJ}$, et al. Adjuvant endocrine therapy for women with hormone receptor-positive breast cancer: ASCO clinical practice guideline focused update. J Clin Oncol. 2019;37(5):423-38.

4. Presant CA, et al. Aromatase inhibitor-associated arthralgia and/or bone pain: frequency and characterization in non-clinical trial patients. Clin Breast Cancer. 2007;7(10):775-8.

5. Niravath P. Aromatase inhibitor-induced arthralgia: a review. Ann Oncol. 2013;24(6):1443-9.

6. Lintermans A, et al. Arthralgia induced by endocrine treatment for breast cancer: a prospective study of serum levels of insulin like growth factor-l, its binding protein and oestrogens. Eur J Cancer. 2014;50(17):2925-31.

7. Weissberger AJ, Ho KK, Lazarus L. Contrasting effects of oral and transdermal routes of estrogen replacement therapy on 24-hour growth hormone $(\mathrm{GH})$ secretion, insulin-like growth factor I, and $\mathrm{GH}$-binding protein in postmenopausal women. J Clin Endocrinol Metab. 1991;72(2):374-81.

8. Leung $\mathrm{KC}$, et al. Estrogen inhibits $\mathrm{GH}$ signaling by suppressing $\mathrm{GH}$ induced JAK2 phosphorylation, an effect mediated by SOCS-2. Proc Natl Acad Sci USA. 2003;100(3):1016-21.

9. Riggs BL, Hartmann LC. Selective estrogen-receptor modulatorsmechanisms of action and application to clinical practice. N Engl J Med. 2003;348(7):618-29.

10. Balili I, Barkan A. Tamoxifen as a therapeutic agent in acromegaly. Pituitary. 2014;17(6):500-4.

11. Cozzi R, et al. Effects of tamoxifen on GH and IGF-I levels in acromegaly. J Endocrinol Invest. 1997;20(8):445-51.

12. Duarte FH, Jallad RS, Bronstein MD. Clomiphene citrate for treatment of acromegaly not controlled by conventional therapies. J Clin Endocrinol Metab. 2015;100(5):1863-9.

13. Kleinberg DL, et al. Growth hormone and insulin-like growth factor-I in the transition from normal mammary development to preneoplastic mammary lesions. Endocr Rev. 2009;30(1):51-74.

14. Farabaugh SM, Boone DN, Lee AV. Role of IGF1R in breast cancer subtypes, stemness, and lineage differentiation. Front Endocrinol (Lausanne). 2015;6:59.

15. Insulin-like growth factor 1 (IGF1), IGF binding protein 3 (IGFBP3), and breast cancer risk: pooled individual data analysis of 17 prospective studies. Lancet Oncol. 2010;11(6):530-542. 
16. Hartog $\mathrm{H}$, et al. Prognostic value of insulin-like growth factor 1 and insulin-like growth factor binding protein 3 blood levels in breast cancer. Breast. 2013;22(6):1155-60.

17. Colletti RB, et al. Effect of tamoxifen on plasma insulin-like growth factor I in patients with breast cancer. Cancer Res. 1989;49(7):1882-4.

18. Yee D. Anti-insulin-like growth factor therapy in breast cancer. J Mol Endocrinol. 2018;61(1):T61-8.

19. Chae YK, et al. Two birds with one stone: octreotide treatment for acromegaly and breast cancer. J Clin Oncol. 2013;31(23):e398-400.
20. Maiza JC, et al. Tamoxifen enhances the control of acromegaly treated with somatostatin analog lanreotide. Pituitary. 2012;15(Suppl 1):S23-7.

\section{Publisher's Note}

Springer Nature remains neutral with regard to jurisdictional claims in published maps and institutional affiliations.
Ready to submit your research? Choose BMC and benefit from:

- fast, convenient online submission

- thorough peer review by experienced researchers in your field

- rapid publication on acceptance

- support for research data, including large and complex data types

- gold Open Access which fosters wider collaboration and increased citations

- maximum visibility for your research: over $100 \mathrm{M}$ website views per year

At BMC, research is always in progress.

Learn more biomedcentral.com/submissions 